\title{
Diseño de una aplicación móvil para diagnosticar plagas en cultivos de maíz
}

\section{Design of a mobile application to diagnose plagues in corn crops}

\author{
HERNÁNDEZ-TAPIA, Zaila†*, REYNA-ÁNGELES, Omar y VENTURA- MAZA, Alejandro \\ Universidad Politécnica de Francisco I. Madero
}

ID $1^{\mathrm{er}}$ Autor: Zaila, Hernández-Tapia / ORC ID: 0000-0003-2564-3451, Researcher ID Thomson: G-6592-2018, CVU CONACYT ID: 622127

ID $1^{\text {er }}$ Coautor: Omar, Reyna-Ángeles / ORC ID: 0000-0001-6604-9059, Researcher ID Thomson: I-3308-2018, CVU CONACYT ID: 097627

ID $2^{\text {do }}$ Coautor: Alejandro, Ventura- Maza / ORC ID: 0000-0002-5425-719X, Researcher ID Thomson: I-6562-2018, CVU CONACYT ID: 168982

\section{Resumen}

La actividad agrícola en el Valle del Mezquital se destaca por la producción de maíz, por lo cual se convierte en una de las principales actividades económicas de la región, sin embargo la producción de este cultivo se ve afectada por diferentes plagas, principalmente de: Gallina ciega (Coleoptera), Gusano Cogollero (Spodoptera frugiperda) y Gusano trozador (Agrotis ípsilon), estos se propagan en ciertas etapas de crecimiento del maíz y suelen ser muy perjudiciales para su desarrollo e incluso pueden ocasionar la pérdida total de la producción, es por ello que el propósito de este trabajo es presentar el diseño de una aplicación móvil, la cual permitirá elegir algunas características para determinar que plaga está atacando el cultivo y con ello abatir a tiempo el daño que puedan ocasionar y disminuir o evitar grandes pérdidas en la producción. Para el desarrollo de este proyecto se implementa la metodología en cascada que consta de 5 etapas requisitos, diseño, implementación, verificación y mantenimiento

Aplicación móvil, Plagas, Maíz

\begin{abstract}
The agricultural activity in the Mezquital Valley is highlighted by the production of corn, which makes it one of the main economic activities of the region, however the production of this crop is affected by different pests, mainly: blind hen (Coleoptera), Worm Cogollero (Spodoptera frugiperda) and Worm Trozador (Agrotis ípsilon), these propagate in certain stages of corn growth and are usually very harmful to their development and may even cause the total loss of production, which is why The purpose of this work is to present the design of a mobile application, which will allow to choose some characteristics to determine which pest is attacking the crop and with it to reduce in time the damage that they can cause and to diminish or to avoid big losses in the production. For the development of this project, the cascade methodology is implemented, consisting of 5 stages, requirements, design, implementation, verification and maintenance.
\end{abstract}

Mobile application, Plagues, Corn

Citación: HERNÁNDEZ-TAPIA, Zaila, REYNA-ÁNGELES, Omar y VENTURA- MAZA, Alejandro. Diseño de una aplicación móvil para diagnosticar plagas en cultivos de maíz. Revista de Tecnología Informática. 2019 3-11: 18-22

\footnotetext{
* Correspondencia del Autor (Correo electrónico: zhernandez@upfim.edu.mx)

$\dagger$ Investigador contribuyendo como primer autor.
} 


\section{Introducción}

En el Municipio de Francisco I. Madero su principal actividad económica ha sido la agricultura que es una de sus fuentes de ingreso más importantes. En esta zona una de las siembras más sustanciales es el maíz, sin embargo estos cultivos muchas veces se ven afectados por diferentes plagas dando como resultado baja producción e incluso pérdida total, lo cual repercute en la economía de muchas familias que solo dependen de ese ingreso. Para tratar de evitar o disminuir estas pérdidas, es necesario detectar las características que presenta el cultivo y que pueden servir como alerta, para actuar de forma inmediata y de ser posible se mitigue la plaga. El artículo está organizado de la siguiente manera: En la sección 2 se presenta el estado del arte, en la sección 3 se encuentra la descripción del problema y metodología aplicada y finalmente en la sección 4 se presentan las etapas realizadas para el logro del diseño de la aplicación móvil.

\section{Estado del Arte}

Existe gran preocupación ya que en los últimos años los agricultores que siembran maíz manifiestan que ya no era redituable, sin embargo la mayoría de la comida mexicana es a base de productos hechos con derivados del maíz.

Plagapp, es un software que a través de reconocimiento de imágenes permite que los agricultores puedan detectar las plagas que están perjudicando sus cultivos, brinda datos sobre tamaño, maneras de erradicarla, ciclo de vida y reproducción. (Tecnología Hortícola, 2019).

Yara CheckIT, Pueden ver fotos de deficiencias en alta resolución, filtrarlos por síntomas, la ubicación de los síntomas en la planta, o por su supuesta causa, permite que los agricultores puedan a mejorar la calidad y aumentar los rendimientos. (Yara México, 2019).

PLANTIX, Ofrece la mayor base de datos independiente para los problemas de las plantas y sus tratamientos, usando un teléfono inteligente con tecnología $3 \mathrm{G}$, plantix puede analizar a través de una foto la información sobre la especie de cultivo sobre su posible enfermedad. (PEAT GmbH, 2015).
Con lo anterior podemos comentar que no existe un sistema enfocado específicamente a la identificación de plagas en el maíz.

\section{Descripción del problema}

Los agricultores no cuentan con una herramienta que les facilite poder hacer un diagnóstico de las posibles plagas que podrían presentar sus cultivos de maíz, lo que genera menor producción del cultivo o perdida de los sembradíos y este a su vez un menor beneficio económico a los agricultores.

\section{Metodología}

El modelo de desarrollo de Software en cascada, es una metodología de la programación muy antigua, que basa en que, no se puede avanzar a la siguiente fase, si la anterior no se encuentra totalmente terminada, pues no tiene por qué haber vuelta atrás. El proceso de desarrollo de software con el modelo de cascada es bastante complejo. Sin embargo, uno de sus principios es que cada una de las fases elaboradas, se encuentre documentada perfectamente, de este modo, si el desarrollo queda suspendido en alguna fase, cualquier usuario que quiera continuar con el proyecto lo podrá hacer leyendo la documentación.

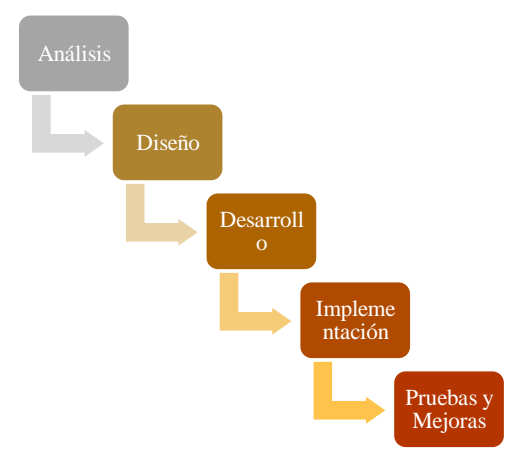

Figura 1 Metodología de desarrollo

Fuente. Elaboración Propia basada en el modelo en Cascada

Análisis. En esta etapa se definen los requerimientos para poder realizar el diseño de la aplicación móvil.

Diseño. Se obtiene la información que será utilizada para la base de datos y presentada al usuario a través de una interface.

Desarrollo. Se estructura la base de datos en un SMBD (Sistema Manejador de Base de Datos), y se realiza la conexión con las interfaces.

HERNÁNDEZ-TAPIA，Zaila，REYNA-ÁNGELES，Omar y VENTURA- MAZA, Alejandro. Diseño de una aplicación móvil para diagnosticar plagas en cultivos de maíz. Revista de Tecnología Informática. 2019 
Implementación. Se inicia esta etapa para que la aplicación sea utilizada y en su caso sea aprobada por el usuario final, de lo contrario será necesario paras a la siguiente etapa.

Pruebas y mejoras. Se inicia esta etapa si existen modificaciones o mejoras que realizar para que el usuario final este satisfecho con la aplicación y esta sea funcional.

\section{Etapas realizadas para el logro del diseño de la aplicación móvil}

1. Análisis. Se determinan los requerimientos para el desarrollo de la aplicación. Se aplicó una entrevista a agricultores con la finalidad de obtener la información necesaria para la detección de las pagas más comunes en los cultivos de maíz.

\section{Entrevista para agricultores-maíz}

1. ¿Cuáles son los nombres de las etapas del maíz, de acurdo a su crecimiento o desarrollo?

2. ¿Cuáles son los tipos de plagas más comunes que afectan el cultivo?

3. Usted sabe detectar de acuerdo a las características que presenta la producción, ¿Qué plaga es la que está afectando?

4. Podría proporcionar las características más importantes que permitirían identificar cada una de las plagas, es decir ¿Cómo detecta las plagas o que características presentan?

5. ¿Qué parte de la producción afectan estas plagas?

6. ¿En qué etapa puede atacar cada una de las plagas?

7. ¿Usted sabe que debe hacer para combatir a tiempo las plagas?

8. Me podría decir ¿Qué usa para combatir cada una de las plagas?

9. ¿Le gustaría contar con una herramienta que le permita obtener de forma inmediata información para detectar el tipo de plaga, así como saber que puede hacer para combatirlas?

10. ¿Hace uso del celular?
De la encuesta se obtuvo la siguiente información: Nombres de las principales plagas, características que se pueden observar en la planta de acuerdo a la plaga que está afectando el cultivo, etapa en que las plagas pueden atacar y alguna recomendación para el control y manejo de dicha plaga.

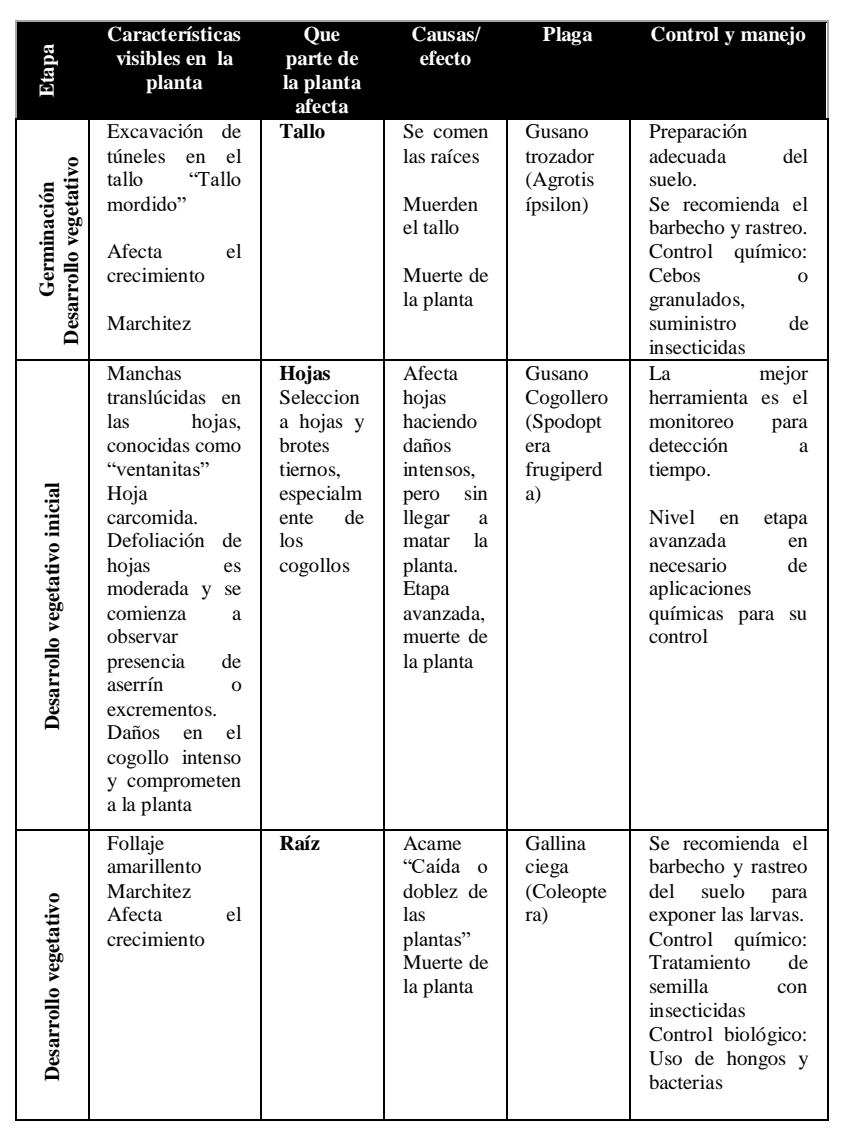

Tabla 1 Información de plagas obtenida de la encuesta aplicada.

\section{Requisitos:}

a) Humanos

- $\quad$ Diseñador gráfico.

- Analista.

- Programador.

- $\quad$ Diseñador de base de datos.

b) Equipo y Software

$\begin{array}{ll}- & \text { Computadora. } \\ - & \text { Internet. } \\ - & \text { Android Studio. } \\ - & \text { Balsamiq. } \\ - & \text { MySQL } \\ - & \text { DIA. }\end{array}$


2. Diseño. Con la información de la etapa del análisis, se inicia con la estructuración del modelo relacional de la base de datos que permitirá almacenar la información del cultivo, las plagas y las posibles soluciones para poder emitir un diagnóstico.

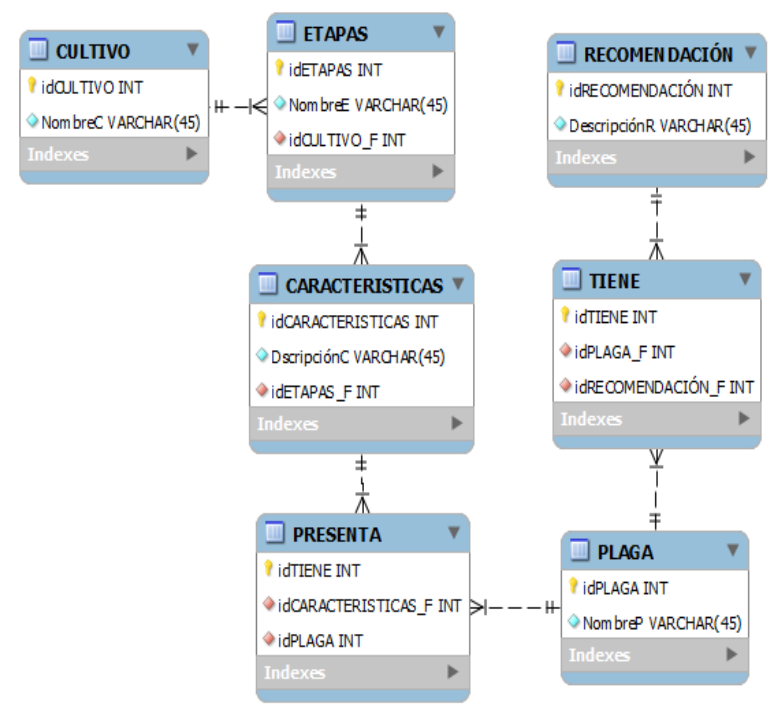

Figura 2 Modelo Relacional

Fuente. Elaboración Propia

Posteriormente se realiza la maquetación de las interfaces necesarias. Inicio de la aplicación

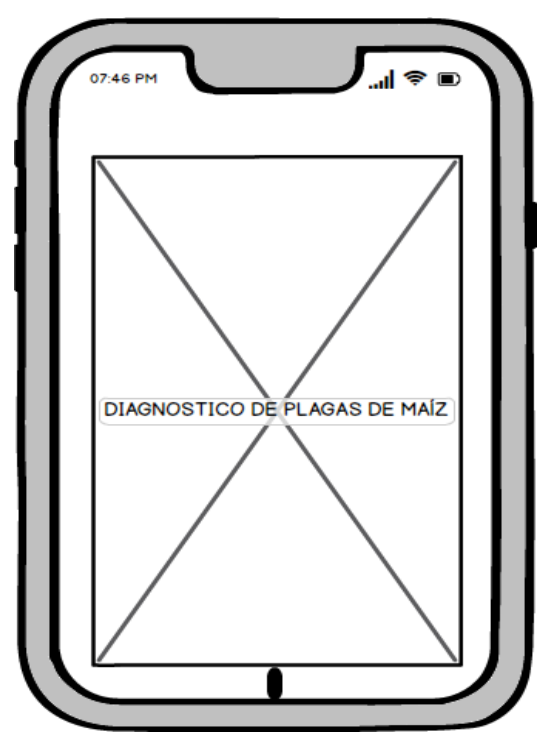

Figura 3 Pantalla de inicio

Fuente. Elaboración Propia

En esta opción el usuario podrá elegir la etapa de su producción para delimitar los resultados según las características que presenta la siembra.

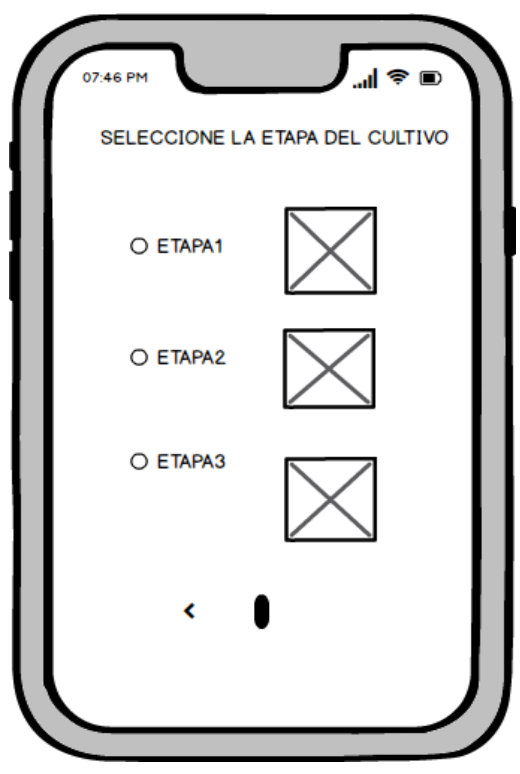

Figura 4 Pantalla de etapas Fuente. Elaboración Propia

En esta pantalla el usuario podrá elegir las características que se presentan en su sembradío y el botón Aceptar permite al usuario ir a la pantalla de resultados.

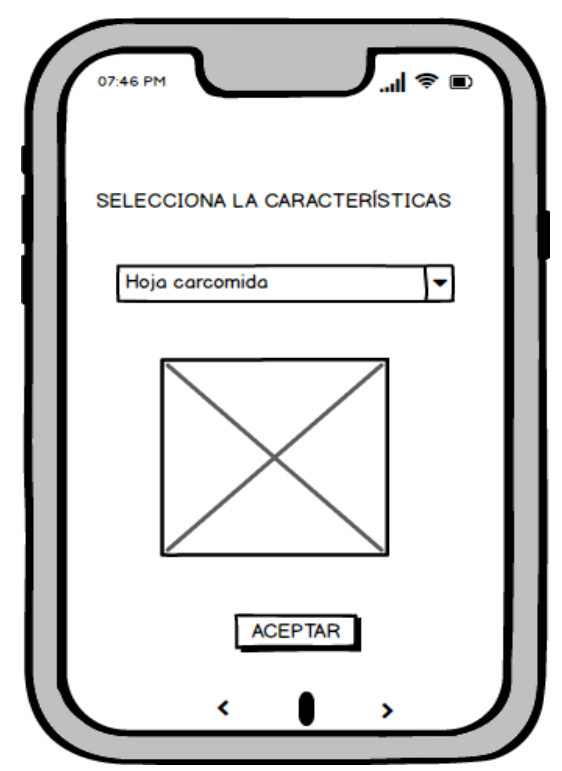

Figura 5 Pantalla de características Fuente. Elaboración Propia

Esta pantalla según las características que presento en el sembradío muestra el resultado de la plaga detectada, así como la recomendación para el control y manejo de dicha plaga. 


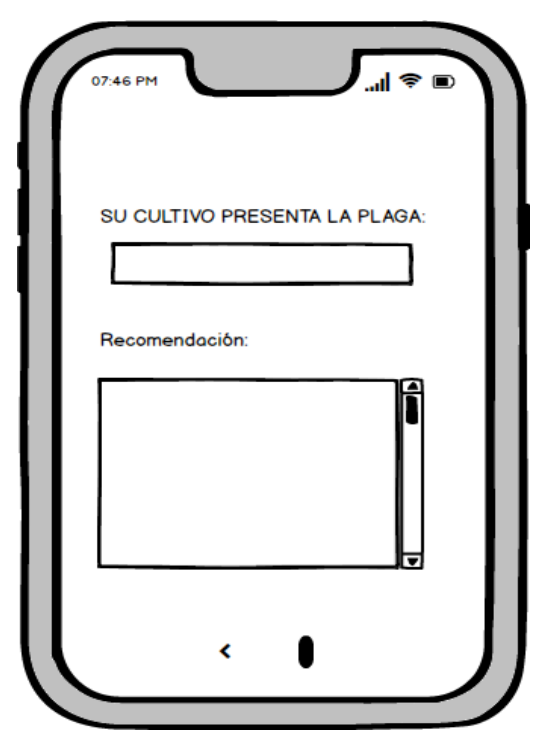

Figura 6 Pantalla de Recomendación Fuente. Elaboración Propia

La información de este artículo de acuerdo a la metodología abarca hasta la etapa 2 "Diseño", sin embargo se inició con la etapa 3 "Desarrollo" de la base de datos.

\section{Resultados y Conclusiones}

Se cuenta con el $100 \%$ de la información necesaria para la aplicación, así como con el diseño de la base de datos y de las interfaces de la aplicación móvil.

\section{Trabajos a futuro}

Con el avance presentado en esta etapa se iniciará el desarrollo de la aplicación móvil para posteriormente implementarla y verificar el funcionamiento, con ello se podrá detectar a tiempo la plaga que se encuentre en los cultivo, lo cual permitirá disminuir perdidas en la producción de maíz.

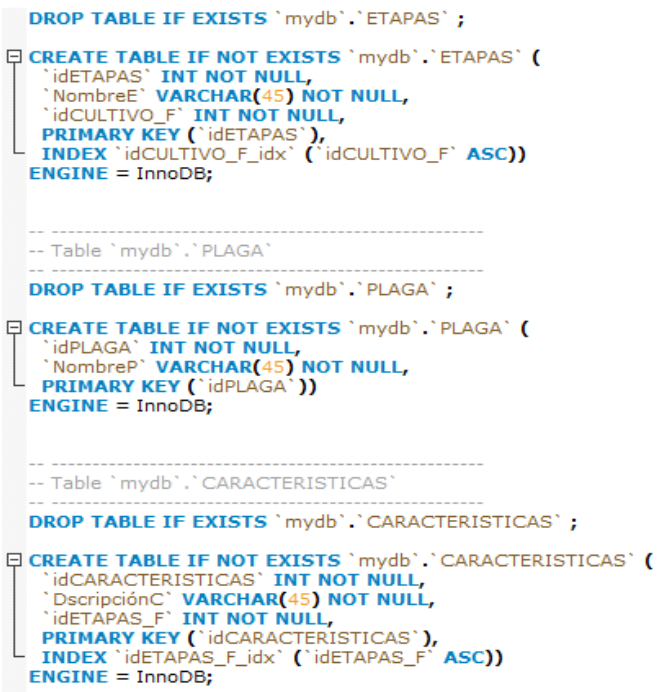

Figura 7 Sección de código de la base de datos en MySQL

\section{Referencias}

Tecnología Hortícola (2019). Plagapp, la aplicación que detecta las plagas en cultivos. Obtenido de Tecnología Hortícola, Frutas, Hortalizas, Olivo, Viña, Viveros y Plantas Ornamentales. Recuperado de: https://www.tecnologiahorticola.com/plagappla-aplicacion-detecta-las-plagas-cultivos/

Yara México (2019). Yara CheckIT. Obtenido de Herramientas y Servicios Yara CheckIT para identificar deficiencias de nutrientes. Recuperado de: https://www.yara.com.mx/nutricionvegetal/herramientas-y-servicios/yara-checkit/

Calle, A., Barnard, B. R. J., Granda Wong, C. A., Javier Alva, J., \& San Martin Zapata, C. E. (2019). Manejo Integrado del Cultivo de Mango Kent.

Moreno Toro, A., \& Salgado Polo, E. (2019). Análisis de cultivo de maíz para ensilaje utilizando imágenes desde un UAV.

García, A. D., Álvarez, M. I. G., Bernal, E. P. G., Diaz, A. M. S., Barrera, F. M. C., Moreno, D. M. L., ... \& Cotes, A. M. Desarrollo y escalamiento de bioplaguicidas.

Urrutia Castro, E. S. (2019). Aplicación de bioestimulantes trihormonales en el cultivo de maíz (Zea mays L.) variedad chingasino para rendimiento de choclo.

Casadei Tajam, M. (2019). Utilidades de los productos obtenidos mediante sensores portados en vehículos aéreos no tripulados en el proceso de agricultura de precisión en Uruguay.

PEAT GmbH. (2015). Plantix | Best Agriculture App. Obtenido de Plantix - the mobile crop doctor for your pocket. Recuperado de: https://plantix.net/en/

INEGI (2019). Agricultura. Obtenido de INEGI Agricultura. Recuperado de: https://www.inegi.org.mx/temas/agricultura/

Producción agrícola (2017). Servicio de Información Agroalimentaria y Pesquera. Obtenido de Producción agrícola. Recuperado de: https://www.gob.mx/siap/acciones-yprogramas/produccion-agricola-33119 